\title{
Effect of the Glycemic Index of Meals on Physical Exercise: A Case Report
}

\author{
Andrea Biagini..$^{*}$, Elisabetta Albi ${ }^{1}$.
}

\begin{abstract}
Carbohydrate uptake before physical exercise allows to maintain plasma glucose concentration. Though, foods or beverages containing the same carbohydrate concentration do not produce the same glycemic and insulin responses which are related to their glycemic index (GI). Last, most studies of $\mathrm{CHO}$ loading have been conducted with male subjects, with the assumption that the results also apply to female athletes.

Sixteen volunteer amateur athletes, eight men and eight women (age $39.1 \pm 7.8 \mathrm{y} ; \mathrm{VO}_{2 \max } 55,7 \pm 11,7 \mathrm{ml} / \mathrm{kg} / \mathrm{min}$ ), were selected and then divided into four groups of four people each one. The trial was divided into several days, one for each group. A carbohydrate source or a placebo (energy $86,5 \pm 6,7 \mathrm{kcal}$; $\mathrm{CHO} 20,0 \mathrm{~g}$; fat $0,3 \pm 0,3 \mathrm{~g}$; protein $0,8 \pm 0,8 \mathrm{~g}$ ) was assigned randomly to each athlete in the group: these supplements differed in the ability to increase blood glucose (banana: high-GI; dried apricots: low-GI; energy gel: mixture of $\mathrm{CHO}$ with different blood release), while the placebo was composed of water, sodium cyclamate, sodium saccharin and acesulfame potassium. Three blood samples were taken from each athlete from finger, by glucometer: one before supplementation, one half an hour later - at the start of the run - and one at the end of the exercise.

Physical activity consisted of 40 minutes run at medium-high intensity, corresponding to $82 \%$ of maximum heart rate or $70 \%$ of $\mathrm{VO}_{2 \max }$. In order to improve the analysis of the results obtained from the detection of biological samples, a questionnaire was submitted to all participants to know their lifestyle and anthropometric and physiological data.

Results highlighted a different glycemic response between men and women, suggesting the consumption of low-GI food rather than high-GI before physical exercise in order to keep plasma glucose levels constant.
\end{abstract}

Keywords: glycemic index, carbohydrate, physical exercise, performance, food supplementation.

${ }^{1}$ Department of Pharmaceutical Sciences, University of Perugia, Perugia, Italy

${ }^{*}$ Corresponding author: Biagini A., Department of Pharmaceutical Science, University of Perugia, Perugia, Italy, andrea. biagini2@studenti.unipg.it.

DOI: $10.2478 /$ ebtj-2020-0021
(C) 2020 Authors. This work was licensed under the Creative Commons AttributionNonCommercial-NoDerivs 4.0 License.

\section{Introduction}

The consumption of exogenous carbohydrates prior to physical activity allows to maintain plasma glucose concentration and limit the depletion of liver and muscle glycogen storage, delaying the onset of the fatigue due to hypoglycemia $(1,2)$. As Hansen et al. from Aalborg University said, a marathon race can be completed faster up to $5 \%$ by applying a scientifically based nutritional strategy rather than applying a freely chosen nutritional strategy (3). Furthermore, it has been demonstrated how the consumption of natural products (e.g. raisins) - compared to energy gels - can have similar benefit on the organism in terms of metabolic effect, athletic performance and gastrointestinal discomfort (4). The latter represents the main disadvantage caused by the fruit intake or any other solid food, which can influence the time of gastric emptying, slowing it down; moreover, the presence of fiber can decrease the intestinal absorption of nutrients like glucose (5, 6). It has also been shown how gastrointestinal problems (2), as well as dehydration (7), can occur after ingestion of hypertonic solutions ( $\mathrm{CHO}$ concentration $>10 \%)$ due to their high osmolarity, which may cause upper GI symptoms such as stomach ache, vomiting and reflux or heartburn (8).

That said, it should be considered that not all foods or drinks containing $\mathrm{CHO}$ produce the same glycemic and insulin responses, even when the composition is the same (9, 10): digestion and absorption not only depend on carbohydrate molecules, but on their 
shape in the food itself too, which determines their glycemic index $(\mathrm{GI})(11,12)$. The GI corresponds to the ratio between the area underlying the blood glucose curve induced by the tested food and the area underlying the glycemic curve induced by a standard (glucose, GI = 100), multiplied by 100 (13). As already said, anyway, blood glucose level is mostly affected by the type of $\mathrm{CHO}$ found in the food, in particular by their bowel absorption and subsequent oxidation in liver or in muscles: so, we consider slow- $\mathrm{CHO}$ - with an oxidation rate of up to $0.6 \mathrm{~g} / \mathrm{min}$ - fructose, galactose, isomaltulose, amylose (starch) and trehalose, and fast- $\mathrm{CHO}$ - with an oxidation up to $1 \mathrm{~g} / \mathrm{min}$ - glucose, sucrose, maltose, maltodextrin (glucose polymers) and amylopectin (starch) (14). The noteworthy first study on glycemic index food applied in sports nutrition was led in 1991 (10), by Thomas and colleagues who demonstrated how $1 \mathrm{~g} /$ $\mathrm{kg}$ CHO meal from low-GI food (lentils) eaten 1 hour prior to cycling at $67 \%$ of $\mathrm{VO}_{2 \max }$ was able to reduce the change in blood glucose levels compared to a high-GI food (potatoes); however, the comparison between low-GI food and glucose did not confirm the differences just found. Subsequently some studies have shown how the intake of low-GI CHO-rich foods allow to limit the post-prandial glycemic peak and support the metabolic response during physical exercise $(11,15)$, as well as reduce glycogen depletion $(16,17)$, while others have suggested how the GI meal does not affect glycogen utilization, although highGI food increases the oxidation rate of triglycerides in muscle (18). Regarding the effects on athletic performance, however, some studies have found benefits from low-GI foods compared to high-GI foods, while others have failed to replicate the same results (10). Furthermore, an important factor in the evaluation of these data come from the definition and measure of the "performance": several studies evaluated performance considering time to exhaustion at a settled pace, whereas in fact in the world of competitive sport a successful performance is determined by the ability of the athlete to cover a certain distance as fast as possible. In conclusion, up to now scientific evidences suggest that the consumption of low-GI, medium-GI or high-GI food 30 minutes prior an intense effort is completely subjective.

In 2004 Carter and colleagues saw how a simple carbohydrate mouth rinse (19) was able to mimic the same advantages as the ingestion of $\mathrm{CHO}$ (2), improving performance by $2-3 \%$ during $1 \mathrm{~h}$ time-trial cycling performance. This suggested the existence of receptors placed on the tongue which, activated by a carbohydrate solution, are able to give rise to a neuronal signalling via sensory afferent fibers and stimulate the reward and pleasure centres in brain, finally modulating the athletic performance. On a physiological level, however, it has been seen that these molecules, whether consumed singularly or in association, do not influence gastric emptying and glycaemic response, as confirmed by a meta-analysis study published in 2018 which involved 741 subjects (20).

Last, it has to be that almost all the scientific literature concerning the supplementation of carbohydrates prior to physical exercise was based on studies conducted on male subjects (21), assuming that the results also apply to female athletes: however, nowadays we know how women would need to increase their total energy intake by $34 \%$ during the carbohydrate loading period to be able to achieve glycogen concentrations similar to those observed in male subjects $(22,23)$, whereas a study has shown how, after a same $\mathrm{CHO}$ ingestion, women were able to increase glycogen stores only by $50 \%$ compared to men (24). During exercise at $75 \%$ of $\mathrm{VO}_{2 \max }$ it was also seen that there are no differences in depletion of glycogen stores, although women tend to oxidize more easily lipid substrates rather than carbohydrate or protein substrates compared to men (22), as a consequence of the greater sensitivity to the lipolytic action exerted by the catecholamines in women rather than in men (25). There is some evidence that the choice of metabolic substrates, in women with eumenorrhea, is also determined by their menstrual status especially during low or moderate intensity exercise (26) - with greater glycogen storage occurring during the luteal phase rather than the follicular phase (27). Although studies are still to be investigated, this is probably due to the activity of $17-\beta$-estradiol, which administered in men (28) and in women with amenorrhea (29) showed a reduction in glucose utilization rate. Furthermore, the administration of 17 - $\beta$-estradiol seemed to increase the activity of enzymes involved in the lipid oxidation pathway, such as carnitin-palmitoil-transferase-1 (CPT-1) (30).

Therefore, the purpose of the study is to evaluate whether and how the intake of different glycemic index and composition meals affects blood glucose during physical exercise.

\section{Material and Methods}

Subjects

Sixteen healthy volunteer runners or triathletes (age 39.1 \pm 7.8 years), who regularly trained at least three times a week ( $8.8 \pm$ 6.2 training hours per week), took part in this study. Athletes were mainly recruited from the Umbrian athletic club ASD Atletica AVIS Magione and from the Tuscan triathlon club JUST Triathlon \& Cycling. Before participation, subjects were fully informed about the purpose and risks associated with the procedures, and a signed informed consent was obtained. All subjects were healthy, as assessed by a general health questionnaire which included their lifestyle, anthropometric and physiological data. The data obtained are reported in compliance with personal data and confidentiality policy. Due to the limitations imposed by the COVID-19 emergency, it was not possible to extend the study to a larger population.

\section{Food choice}

Food choice was based on the different ability to raise blood glucose (banana: high-GI; dried apricots: low-GI), adding an energy gel commonly used by athletes during their training or competitions, which was made out of a mixture of carbohydrates with different release in the blood (DP4 glucose, fructose, maltodextrin, trehalose, isomaltulose), and low joule drink as placebo, made up of water, sodium cyclamate, sodium saccharin and acesulfame K (Tab. 1). Foods were randomly assigned (single blind) to the participants, so as each supplement was taken by four different athletes (two men and two women). To promote digestion and absorption of nutrients, avoiding an excessive recall of liquids in the lumen of intestine, especially after the energy gel ingestion, water ad libitum was supplied to the athletes. 
Table 1. Nutritional values.

\begin{tabular}{|c|c|c|c|c|}
\hline Supplement & Energy (kcal) & $\begin{array}{c}\text { Carbohydrate } \\
\text { (sugars, g) }\end{array}$ & Fat (g) & Protein $(\mathrm{g})$ \\
\hline Energy gel (25ml) & 81 & $20,0(3,8)$ & 0 & 0 \\
\hline Banana (130g) & 84,5 & $20,0(16,6)$ & 0,4 & 1,6 \\
\hline Dried apricots $(30 \mathrm{~g})$ & 94 & $20,0(17,2)$ & 0,5 & 0,9 \\
\hline Placebo & - & - & - & - \\
\hline Mean $\pm \mathrm{SD}^{*}$ & $86,5 \pm 6,7$ & $20,0 \pm 0,0$ & $0,3 \pm 0,3$ & $0,8 \pm 0,8$ \\
\hline
\end{tabular}

Nutritional values of supplements taken by the athletes during the trial. All values were obtained from the nutritional facts label of each food. Mean \pm SD.

\section{Blood glucose measurements}

Subjects reached the trial camp after a 3-4 h fast, refraining from eating fatty food or assuming food or beverages containing nerve substances (coffee, tea, chocolate, cocoa). For each athlete, three blood samples $(0,6 \mu \mathrm{l})$ were taken to measure instant blood glucose, using a glucometer (device and test strips: Accu-Chek Guide) after finger puncture (lancing device and lancets: OneTouch ${ }^{\bullet}$ Delica ${ }^{\circ}$ ). The first detection was carried out "at supplementation"; the second was performed after 30 minutes, at the theoretical glycemic peak (31). At the end of the measurement, athletic performance started. The third and final detection was carried out at the end of the $40 \mathrm{~min}$ run.

\section{Physical exercise}

Physical exercise consisted of $40 \mathrm{~min}$ run at $82 \%$ of their HR$\max$ - corresponding to $70 \%$ of their $\mathrm{VO}_{2 \max }$. The trial lasted several days, one for each group. Athletes checked their heart rate through a personal sport watch which provided heart rate monitoring either with a belt or from the wrist. As mentioned, the activity started immediately after the second blood glucose measurement, thirty minutes after taking the supplement.

Predicted $\mathrm{VO}_{2 \max }$ equation:

$\mathrm{VO}_{2 \max }=15 \times\left(\mathrm{HR}_{\max } \div \mathrm{HR}_{\text {rest }}\right)(32)$

Relationship between $\% \mathrm{HR}_{\max }$ and $\% \mathrm{VO}_{2 \max }$ :

$\% \mathrm{HR}_{\max }=37+\left(\% \mathrm{VO}_{2 \max } \times 0.64\right)(33)$

\section{Statistical analysis}

The data obtained from the trial were compared by using a twotailed F-test for variances. Data evaluation was performed by using Microsoft ${ }^{\circ}$ Excel $^{\circ} 2016$ 64-bit Edition for Windows 10. All data are reported as mean \pm SD. Statistical significance was set at $\mathrm{p}<0,05$.

\section{Results}

All the athletes involved in the study followed an omnivorous diet with a daily consumption of fruit and vegetables as well as cereals, milk and yogurt. According to the information given by the questionnaires, no one had a vegetarian or vegan diet. Exposure to alcohol and cigarette smoking was limited to rare cases. There is a difference in training hours between the group of runners and the group of triathletes (5 subjects out of 16), who inevitably sustain a higher weekly workload: therefore, that may positively influence body's ability to oxidize fat storage, saving muscle and hepatic glycogen. All population data are provided in (Tab. 2).

Physiological differences were also observed in the aerobic fitness level between the two sexes, expressed through the calculation of the $\mathrm{VO}_{2 \max }(62.2 \pm 8.3 \mathrm{ml} / \mathrm{kg} / \mathrm{min}$ for men; $49.1 \pm$ $11.7 \mathrm{ml} / \mathrm{kg} / \mathrm{min}$ for women), i.e. the maximum volume of oxygen that the body can consume per unit of time per muscle contraction (Tab. 3).

For what concerns plasma glucose levels, it should be remembered how athletes were at least on a three hours fast - having refrained from eating fatty food or assuming food or beverages containing nerve substances. In the data provided below, there is a difference between the average blood glucose levels detected in men and women (Tab. 4): specifically, average results are greater in female subjects - where the values obtained at the second and third measurements, i.e. thirty minutes after supplement ingestion and then at the end of the physical exercise, are higher, too - whilst in men blood glucose levels remain almost constant, especially in the last two measurements.

Banana, which was the high-GI food, had a greater impact on women's blood glucose than on men's one, causing a huge reduction of glycemia from the start to the end of the physical exercise, in contrast with what was observed in men: moreover, almost all subjects confirmed abdominal pain and difficult digestion following the banana consumption, with negative effects on their performance. It must be said that these disorders have been reported, albeit in just one case, also following the consumption of dried apricots, which forced the athlete to stop running for a while and then restart, due to a severe pain in the right hypochondriac region. Consumption of dried apricots, chosen as a low-GI food, did not alter significantly blood glucose levels, guaranteeing fairly stable values at the end of the exercise, as expected; however, in one case the third measure of blood glucose level was considerably lower than the first one: the athlete confirmed he had suffered in the finale. On the other hand, energy gel did not cause gastrointestinal problems, potentially due to its hygroscopic action, allowing both sexes 
Table 2. Population characteristics.

\begin{tabular}{|c|c|c|c|c|c|c|}
\hline Population & Gender & Age (years) & Height $(\mathrm{m})$ & Weight $(\mathrm{kg})$ & $\begin{array}{c}\text { BMI }\left(\mathrm{kg} / \mathrm{m}^{2}\right) \\
\text { Weekly worklo- } \\
\text { ad (h) }\end{array}$ \\
\hline 8 & M & $39,0 \pm 4,6$ & $1,76 \pm 0,06$ & $70,8 \pm 4,2$ & $22,8 \pm 1,2$ & $8,9 \pm 6,7$ \\
\hline 8 & W & $39,3 \pm 10,5$ & $1,64 \pm 0,04$ & $55,7 \pm 6,1$ & $20,8 \pm 1,6$ & $8,6 \pm 6,2$ \\
\hline 16 & M+W & $39,1 \pm 7,8$ & $1,70 \pm 0,08$ & $63,2 \pm 9,3$ & $21,8 \pm 1,7$ & $8,8 \pm 6,2$ \\
\hline
\end{tabular}

Population characteristics derived from the submitted questionnaire which included lifestyle, anthropometric and physiological data of the subjects involved in the study. Mean \pm SD.

Table 3. Heart rate and $\mathrm{VO}_{2} \max$ data.

\begin{tabular}{|c|c|c|c|c|}
\hline \multicolumn{3}{|c|}{ Athletes } & \multicolumn{4}{c|}{ Heart rate $(\mathrm{bpm})$} \\
\hline No. & Gender & At rest & Max & $\mathrm{VO}_{2 \max }(\mathrm{ml} / \mathrm{kg} / \mathrm{min})$ \\
\hline 8 & $\mathrm{M}$ & $47,8 \pm 8,2$ & $186,3 \pm 6,0$ & $62,2 \pm 8,3$ \\
\hline 8 & $\mathrm{~W}$ & $58,9 \pm 10,6$ & $187,3 \pm 13,8$ & $49,1 \pm 11,7$ \\
\hline 16 & $\mathrm{M}+\mathrm{W}$ & $53,3 \pm 10,8$ & $186,8 \pm 10,8$ & $55,7 \pm 11,7$ \\
\hline
\end{tabular}

Heart rate data derived from the submitted questionnaire, whereas $\mathrm{VO}_{2 \max }$ was estimated through a predicted equation, as reported in Physical exercise paragraph. Mean \pm SD.

Table 4. Comparison of glycemia means between men and women groups.

\begin{tabular}{|c|c|c|c|c|c|}
\hline \multicolumn{1}{|c|}{ Athletes } & \multicolumn{3}{|c}{ Glycemia (mg/dl) } \\
\hline No. & Gender & At suppl. & Start of activity & End of activity \\
\hline 8 & M & $98,9 \pm 12,5$ & $109,1 \pm 20,3$ & $108,1 \pm 10,3$ \\
\hline 8 & W & $95,5 \pm 10,5$ & $123,0 \pm 47,6$ & $165,8 \pm 28,9$ \\
\hline 16 & M+W & $98,0 \pm 11,3$ & $115,9 \pm 36,1$ & $123,7 \pm 25,4$ \\
\hline
\end{tabular}

Differences in blood glucose between sexes were observed through the three measures performed during the trial: the first with the athletes still fasting, before the supplementation; the second $30 \mathrm{~min}$ after the supplementation (at the start of the run) and the last at the end of the $40 \mathrm{~min}$ run. Mean \pm SD.

to maintain good blood sugar levels thanks to the gradual release of different sugars into the blood (DP4 glucose, fructose, maltodextrin, trehalose, isomaltulose); however, a reduction in blood sugar was observed in men at the end of the last measurement, whilst in women it turned out slightly higher. Even feelings reported at the end of the $40 \mathrm{~min}$ run were positive. Finally, subjects treated with placebo (water plus sweetener) showed a reduction of blood glucose levels between the second and the third measurement, with similar data observed in the last sample compared to those obtained from subjects treated with dried apricots. All data are available in (Tab. 5) and (Fig. la and $1 \mathrm{~b})$, provided below.

\section{Discussion}

The study included men and women in equal parts for a total of 16 subjects, taking as reference the largest population found in previous studies. However - unlike the previous studies ours tried to simulate an everyday life activity, and that is why little quantities of common food or supplements ( $20 \mathrm{~g}$ of $\mathrm{CHO}$ ) were consumed by athletes ( $130 \mathrm{~g}$ banana, $30 \mathrm{~g}$ dried apricots, $25 \mathrm{ml}$ energy gel), in a time frame of $30 \mathrm{~min}$ that can be easily reproduced daily: it is unthinkable to be able to consume up to $2-2,5 \mathrm{~g} / \mathrm{kg}$ of $\mathrm{CHO}$ from lentils or potatoes one hour before the exercise (10), since there would be a risk of gastrointestinal problems due to an inadequate digestion; as already said, only $130 \mathrm{~g}$ of banana consumed by the athletes in this study caused problems in three out of four subjects for the same reason. Moreover, the study highlighted the different glycemic response between men and women after the consumption of the same amount of $\mathrm{CHO}$ provided by different GI-meals. It was seen that the consumption of high-GI food corresponded to a greater increase in pre-exercise blood glucose and a greater decrease in blood glucose levels at the end of the exercise, compared to what was observed in subjects who instead had consumed low-GI food: this difference was more notable especially in female population, as shown in (Fig. 1b) attached below. The 
Table 5. Blood glucose measures.

\begin{tabular}{|c|c|c|c|c|c|}
\hline \multicolumn{2}{|c|}{ Athletes } & & \multicolumn{3}{|c|}{ Glycemia (mg/dl) } \\
\hline No. & Gender & Supplement & At suppl. & Start of activity & End of activity \\
\hline 2 & M & Banana & $92,0 \pm 9,9^{* *}$ & $102,5 \pm 13,4^{\star \star}$ & $108,5 \pm 19,1^{\star *}$ \\
\hline 2 & W & Banana & $91,5 \pm 9,2^{\star *}$ & $178,5 \pm 85,6^{* *}$ & $111,5 \pm 21,9^{* *}$ \\
\hline 4 & $\mathrm{M}+\mathrm{W}$ & Banana & $91,8 \pm 7,8$ & $140,5 \pm 66,5$ & $110,0 \pm 16,9$ \\
\hline 2 & M & Dried apricots & $108,5 \pm 24,7^{\star *}$ & $112,5 \pm 13,4^{\star *}$ & $99,5 \pm 6,4^{* *}$ \\
\hline 2 & W & Dried apricots & $103,5 \pm 4,9^{*}$ & $109,5 \pm 6,4^{\star}$ & $137,0 \pm 35,4^{\star}$ \\
\hline 4 & $\mathrm{M}+\mathrm{W}$ & Dried apricots & $106,0 \pm 14,9$ & $111,0 \pm 8.8$ & $118,3 \pm 30,0$ \\
\hline 2 & M & Energy gel & $95,0 \pm 7,1^{\star *}$ & $133,5 \pm 9,2^{* *}$ & $115,5 \pm 7,8^{* *}$ \\
\hline 2 & W & Energy gel & $88,0 \pm 12,7^{\star *}$ & $109,5 \pm 2,1^{\star *}$ & $157,5 \pm 33,2^{* *}$ \\
\hline 4 & $\mathrm{M}+\mathrm{W}$ & Energy gel & $91,5 \pm 9,3$ & $121,5 \pm 14,9$ & $136,5 \pm 31,2$ \\
\hline 2 & M & Placebo & $100,0 \pm 4,2^{\star *}$ & $88,0 \pm 15,6^{* *}$ & $109,0 \pm 4,2^{* *}$ \\
\hline 2 & W & Placebo & $99,0 \pm 14,1^{*}$ & $94,5 \pm 3,5^{\star}$ & $137,0 \pm 29,7^{\star}$ \\
\hline 4 & $\mathrm{M}+\mathrm{W}$ & Placebo & $99,5 \pm 8,5$ & $91,3 \pm 9,9$ & $123,0 \pm 23,7$ \\
\hline
\end{tabular}

Differences in blood glucose were observed both between sexes and type of supplementation consumed, as pointed out by the three measures performed during the trial. Mean $\pm S D ;{ }^{*} \mathrm{p}<0,05$ : significant differences, $M$ : ban vs en.gel; W: ban vs plac, dr.apr vs en.gel, en.gel vs plac; ${ }^{*} \mathrm{p}<0,01$ : significant differences, $M$ : dr.apr vs en.gel, en.gel vs plac; W: ban vs en.gel; $M-W$ : ban vs ban.

Figure 1. Changes of blood glucose levels during the trial.

a.

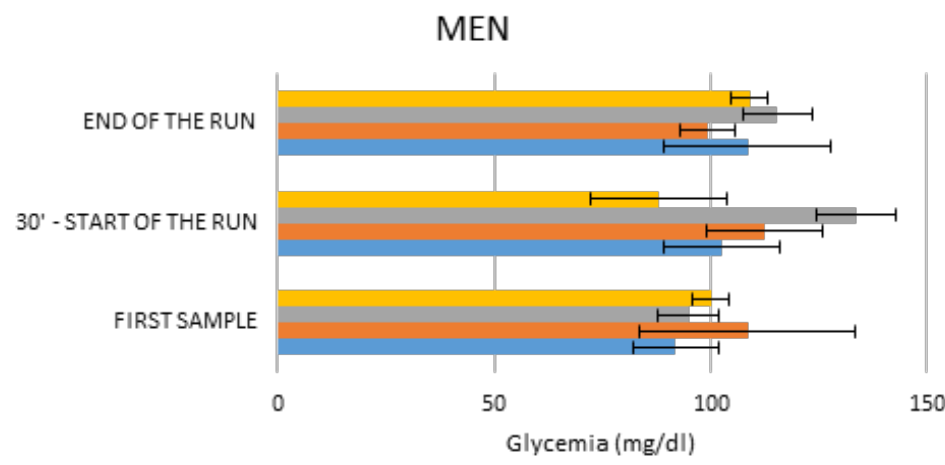

Placebo Energygel Dried apricots Banana

b.

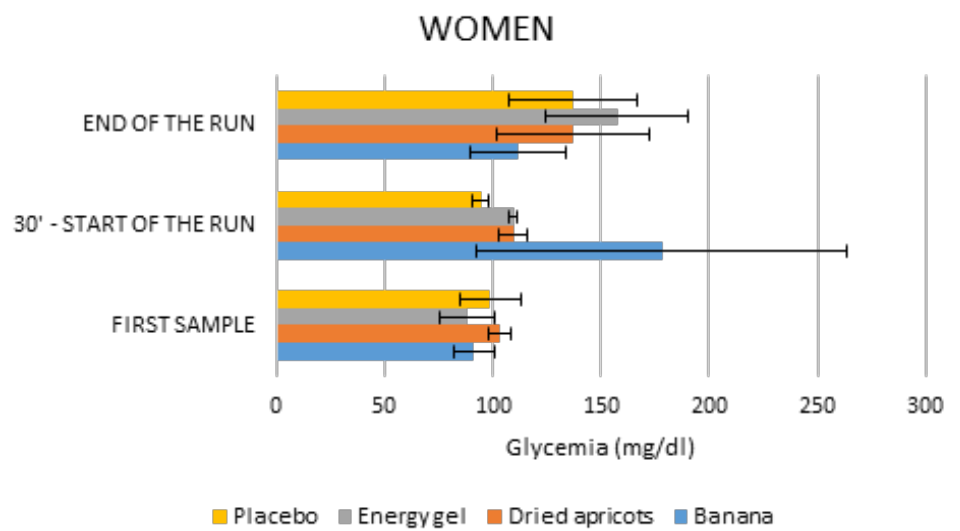

Differences between men and women are expressed in illustrations Figure 1a and 1b, which show all the changes in blood glucose levels occurred during the three phases of the trial. Mean \pm SD. 
data reported in (Tab. 4) also show that women values acquired half an hour after the ingestion of different foods, as well as at the end of the trial, were not only higher than those found in male population but more fluctuating, too. The high plasma glucose levels at the end of the activity ( $165.8 \pm 28.9$ vs 108.1 $\pm 10.3 \mathrm{mg} / \mathrm{dl}$ ) are probably explained by a better oxidation of the fatty substrate rather than the carbohydrate or protein ones, thanks to a greater catecholaminergic response that induces lipolysis (25).

The study did not reveal any difference in performance between athletes at the same level despite of the different supplements taken. However, considering gastrointestinal problems related to the consumption of banana already described above, it is recommended not to take it in the half hour before physical exercise, also in order not to experience a glycemic peak followed by a physiological drop $(91.8 \pm 7.8 ; 140.5 \pm 66.53 ; 110.0$ $\pm 16.9 \mathrm{mg} / \mathrm{dl}$ ): just in one case, concerning a male subject, an increase in blood glucose occurred at the end of physical activity after the banana consumption $(85 ; 112 ; 122 \mathrm{mg} / \mathrm{dl})$. On the other hand, it can be said that - unlike what Too and colleagues said - the consumption of dried apricots in place of the energy gel gave positive results as regards the maintenance of blood glucose levels, which remained constant throughout the entire 40 min run $(106.0 \pm 14.9 ; 111.0 \pm 8.8 ; 118.3 \pm 30.0$ $\mathrm{mg} / \mathrm{dl}$ ), whilst it gave negative results as a "natural" alternative to food supplements, since several subjects complained lack of strength in the finale: this result is in contrast with the starting expectations, which saw it as a possible natural alternative to an industrial product like the energy gel. Furthermore, although the energy gel should be consumed during physical activity according to the recommendation reported on the label - it is commonly used also before training, giving positive results in terms of maintaining blood glucose $(91.5 \pm 9.3 ; 121.5 \pm 14.9$; $136.5 \pm 31.2 \mathrm{mg} / \mathrm{dl}$ ), energy and performance, since no athlete complained lack of energy in the finale nor gastrointestinal discomfort, despite the high hygroscopic effect due to its high sugar content and the reduced amount of water in it. As expected, the placebo drink added with sweeteners did not affect blood glucose level.

\section{Conclusions}

To sum up, results highlighted the different glycemic responses between men and women after the consumption of a same amount of $\mathrm{CHO}$ from different glycemic index foods, demonstrating how the ingestion of low-GI foods is advisable to that of high-GI foods in order to keep plasma glucose levels constant during physical activity; nevertheless, it must be said that the consumption of dried apricots in replacement of an industrial product (energy gel) is not recommended, since the athletes who took them complained lack of strength in the final stages of the run. No interference was observed on plasma glucose levels by the sweeteners added to the placebo solution.

\section{Acknowledgements}

We thank the sixteen volunteers who, through their willing- ness, have made the fulfillment of this project possible.

\section{Ethical Review and Approval}

The study was approved by the University Committee of Bioethics of the University of Perugia, protocol no. 51856, 11 June 2020.

Before participation, a signed informed consent was obtained from each subject.

\section{Disclosures}

The authors declare no conflict of interest.

\section{References}

1. Karelis AD, Smith JEW, Passe DH, et al. Carbohydrate Administration and Exercise Performance. Sports Med 2010;40(9):747-763.

2. Jeukendrup AE. Carbohydrate feeding during exercise. European Journal of Sport Science 2008;8:2,77-86.

3. Hansen EA, Emanuelsen A, Gertsen RM, et al. Effect of freely chosen vs. a scientifically based nutritional strategy on marathon race performance. Journal of the International Society of Sports Nutrition 2013;10(Suppl 1):P8;

4. Too B et al. Natural versus commercial carbohydrate supplementation and endurance running performance. Journal of the International Society of Sports Nutrition 2012;9:27.

5. Capuano E. The behavior of dietary fiber in the gastrointestinal tract determines its physiological effect. Critical Reviews in Food Science and Nutrition 2017;57:16,35433564.

6. Dhital S, Dolan G, Stokes J. et al. Enzymatic hydrolysis of starch in the presence of cereal soluble fibre polysaccharides. Food Funct 2014; 5:579-586.

7. Evans GH, Shirreffs SM, Maughan RJ. Acute effects of ingesting glucose solutions on blood and plasma volume. Brit J Nutr 2009;101:1503-8.

8. Jentjens, RLPG, Moseley L, Waring RH, et al. Oxidation of combined ingestion of glucose and fructose during exercise. J Appl Physiol 2004;96:1277-1284.

9. Wong SHS, Sui PM, Lok A, et al. Effect of the glycaemic index of pre-exercise carbohydrate meals on running performance. Eur J Sports Sci 2008;8:23-33.

10. Cazal MM, Alfenas RCG, Peluzio MCG, et al. Impact of meal's glycemic index pre-exercise in the performance. J Anal Pharm Res. 2018;7(3):289-296.

11. DeMarco HM, Sucher KP, Cisar CJ, et al. Pre-exercise carbohydrate meals: application of glycemic index. Med Sci Sports Exerc 1999;31:164-70.

12. Moore LJ, Midgley AW, Thurlow S, et al. Effect of the glycaemic index of a pre-exercise meal on metabolism and cycling time trial performance. J Sci Med Sport 2010;13:1828.

13. Rytz A, Adeline D, Lê KA, et al. Predicting Glycemic Index and Glycemic Load from Macronutrients to Accelerate Development of Foods and Beverages with Lower Glucose Responses. Nutrients 2019;11(5):1172.

14. Burke LM, Deakin V. Clinical Sports Nutrition (5th edition). McGraw-Hill Education 2015;13:386. 
15. Wee SL, Williams C, Gray S, et al. Influence of high and low glycemic index meals on endurance running capacity. Med Sci Sports Exerc 1999;31:393-9.

16. Wee SL, Williams C, Tsintzas K, et al. Ingestion of high-glycemic index meal increases muscle glycogen storage at rest but augments its utilization during subsequent exercise. J Appl Physiol 2005;99:707-14.

17. Febbraio MA, Keenan J, Angus DJ, et al. Preexercise carbohydrate ingestion, glucose kinetics, and muscle glycogen use: effect of the glycemic index. J Appl Physiol 2000;89:1845-51.

18. Stevenson EJ, Thelwall PE, Thomas K, et al. Dietary glycemic index influences lipid oxidation but not muscle or liver glycogen oxidation during exercise. Am J Physiol Endocrinol Metab 2009;296:E1140-7.

19. Carter JM, Jeukendrup AE, Jones DA. The effect of carbohydrate mouth rinse on 1-h cycle time-trial performance. Medicine and Science in Sports and Exercise 2004;36, 2107-2111.

20. Nichol AD, Holle MJ, An R. Glycemic impact of non-nutritive sweeteners: a systematic review and meta-analysis of randomized controlled trials. Eur J Clin Nutr 2018;72,796-804.

21. Volpe SL. Glycemic Index and Athletic Performance. ACSM's Health \& Fitness Journal 2011;15(1):32-33.

22. Tarnopolsky MA. Females and males: Should nutritional recommendations be gender specific? Schweiz Z Med Traumatol 2003;51(1):39-46.

23. Wismann J, Willoughby D. Gender Differences in Carbohydrate Metabolism and Carbohydrate Loading. J Int Soc Sports Nutr 2006;3,28.

24. Walker JL, Heigenhauser GJ, Hultman E, et al. Dietary carbohydrate, muscle glycogen content, and endurance performance in well-trained women. J Appl Physiol 2000;88:2151-8.

25. Horton TJ, Dow S, Armstrong M, Donahoo WT. Greater systemic lipolysis in women compared with men during moderate-dose infusion of epinephrine and/or norepinephrine. J Appl Physiol 2009;107(1):200-210.

26. Romijn JA, Coyle EF, Sidossis LS, et al. Substrate metabolism during different exercise intensities in endurance-trained women. J Appl Physiol 2000;88:1707-14.

27. McLay RT, Thomson CD, Williams SM, et al. Carbohydrate Loading and Female Endurance Athletes: Effect of Menstrual-Cycle Phase. International Journal of Sport Nutrition and Exercise Metabolism 2007;17:189-205.

28. Carter SL, Rennie CD, Hamilton SJ, et al. Changes in skeletal muscle in males and females following endurance training. Can J Physiol Pharmacol 2001;79:386-92.

29. Tarnopolsky MA. Sex differences in exercise metabolism and the role of 17-beta estradiol. Med Sci Sports Exerc 2008;40(4):648-54.

30. Campbell SE, Febbraio MA. Effect of ovarian hormones on mitochondrial enzyme activity in the fat oxidation pathway of skeletal muscle. Am J Physiol Endocrinol Metab 2001,281:E803-8.

31. Chung ST, Ha J, Onuzuruike AU, Kasturi K, et al. Time to glucose peak during an oral glucose tolerance test identifies prediabetes risk. Clinical endocrinology 2017;87(5):484-
491.

32. Uth $\mathrm{N}$ et al. Estimation of $\mathrm{VO} 2$ max from the ratio between Hrmax and Hrrest - the Heart Rate Ratio Method. Eur J Appl Physiol 2004;91(1):111-115.

33. Swain et al. Target HR for the development of CV fitness. Medicine \& Science in Sports \& Exercise 1994;26 (1):112116. 